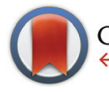

CrossMark \& click for updates

Cite this: Analyst, 2016, 141, 6507

Received 21st June 2016 , Accepted 27th October 2016

DOI: $10.1039 / c 6 a n 01409 g$

www.rsc.org/analyst

\section{Image analysis for a microfluidic paper-based analytical device using the CIE $L^{*} a * b *$ color system $\uparrow$}

\author{
Takeshi Komatsu, ${ }^{a}$ Saeed Mohammadi, ${ }^{a}$ Lori Shayne Alamo Busa, $\xi^{a}$ \\ Masatoshi Maeki, ${ }^{b}$ Akihiko Ishida, ${ }^{\text {b }}$ Hirofumi Tani ${ }^{b}$ and Manabu Tokeshi*b,c,d,e
}

\begin{abstract}
The combination of a microfluidic paper-based analytical device $(\mu P A D)$ and digital image analysis is widely used for quantitative analysis with $\mu$ PADs because of its easy and simple operation. Herein, we have demonstrated a quantitative analysis based on multiple color changes on a $\mu$ PAD. The CIE $L^{*} a * b *$ color system was employed to analyse the digital images obtained with the $\mu P A D$. We made $\mathrm{pH}$ measurements using a universal $\mathrm{pH}$-indicator showing multiple color changes for various $\mathrm{pH}$ values of aqueous test solutions. The detectable $\mathrm{pH}$ range of this method was wider than the typical grayscale-based image analysis, and we succeeded in the measurements for a wide $\mathrm{pH}$ range of 2-9.
\end{abstract}

Since the first report of a $\mu \mathrm{PAD}$ in 2007 by Whitesides's group as an inexpensive analytical and diagnostic device, ${ }^{1} \mu$ PADs have steadily gained attention and interest among researchers. ${ }^{2-4}$ The $\mu$ PADs have a great potential as analytical devices in resource-limited settings because they are inexpensive, easy-to-use and require no special measuring instruments. Several types of fabrication methods have been developed including photolithography, ${ }^{5,6}$ screen printing, ${ }^{7}$ wax printing, ${ }^{8,9}$ inkjet printing ${ }^{10,11}$ and cutting. ${ }^{12}$ Several detection methods for the $\mu$ PADs have also been proposed such as colorimetric, ${ }^{1,6}$ fluorescence, ${ }^{13}$ electrochemical, ${ }^{7}$ and electrochemiluminescence ${ }^{14}$ methods. In these detection methods,

\footnotetext{
${ }^{a}$ Graduate School of Chemical Sciences and Engineering, Hokkaido University, Kita 13 Nishi8, Kita-ku, Sapporo 060-8628, Japan

${ }^{b}$ Division of Applied Chemistry, Faculty of Engineering, Hokkaido University, Kita 13 Nishi 8, Kita-ku, Sapporo 060-8628, Japan.

E-mail: ishida-a@eng.hokudai.ac.jp; Fax: +81-11-706-6745; Tel: +81-11-706-6746

${ }^{c}$ ImPACT Research Centre for Advanced Nanobiodevices, Nagoya University,

Furo-cho Chikusa-ku, Nagoya 464-8603, Japan

${ }^{d}$ Innovative Research Centre for Preventive Medical Engineering, Nagoya University, Furo-cho Chikusa-ku, Nagoya 464-8603, Japan

${ }^{e}$ Institute of Innovation for Future Society, Nagoya University, Furo-cho, Chikusa-ku, Nagoya 464-8603, Japan. E-mail: tokeshi@eng.hokudai.ac.jp; Fax: +81-11-706-6745; Tel: +81-11-706-6744

$\dagger$ Electronic supplementary information (ESI) available. See DOI: 10.1039/ c6an01409g

\$Present address: Natural Science Department, College of Arts and Sciences, Nueva Vizcaya State University, Bayombong, Nueva Vizcaya 3700 Philippines.
}

colorimetric methods based on an image analysis of digital images of the device are most widely used because they are simple and easy-to-use. These methods require no special apparatus, only a digital camera or a smartphone, and allow quantitative analysis by reading out the color information (RGB value or CMYK value) of the detection area of a $\mu$ PAD in the digital image. The color information is mainly obtained as separate RGB channel values or grayscale, which give the amount of analyte on the basis of the relationship between the color information and the analyte concentration. Several software applications for smartphones have been developed to perform image analysis of the $\mu \mathrm{PAD}$ images. ${ }^{15,16}$ Therefore, a combination of $\mu$ PADs and image analysis is a suitable technique for point of care testing and applications in resourcelimited settings. The grayscale (the average of RGB values) is one of the most common measure in image-analysis based colorimetry. ${ }^{6,17-19}$ However, the grayscale possibly does not allow quantitative analysis based on multiple changes of color such as a universal $\mathrm{pH}$ test strip because the grayscale cannot follow multiple color changes.

Herein, we report a simple colorimetric $\mathrm{pH}$ measurement method using a $\mu$ PAD based on the CIE $L^{*} a^{*} b^{*}$ color system. The CIE $L^{*} a^{*} b^{*}$ color system has three coordinates $L^{*}, a^{*}$, and $b^{*}$. The $L^{*}$ value indicates lightness, and $\left(a^{*}+b^{*}\right)^{1 / 2}$ and $\tan ^{-1}\left(b^{*} / a^{*}\right)$ indicate chroma $\left(C_{\mathrm{ab}}\right)$ and hue angle $\left(h_{\mathrm{ab}}\right)$, respectively. The color difference $(\Delta E)$ between an objective color and a reference one is given by the following equation: ${ }^{20-22}$

$$
\Delta E=\sqrt{\left(a_{x}-a_{0}\right)^{2}+\left(b_{x}-b_{0}\right)^{2}+\left(L_{x}-L_{0}\right)^{2}}
$$

where subscripts $x$ and 0 denote objective and reference, respectively. Abe et al. ${ }^{11}$ previously demonstrated the $\mathrm{pH}$ measurement using a universal $\mathrm{pH}$ indicator and the $a^{*}$ coordinate. However, the reported method did not cover a wide $\mathrm{pH}$ range because of lack of color information. The $a^{*}$ coordinate indicates redness and greenness for the positive $\left(+a^{*}\right)$ and negative $\left(-a^{*}\right)$ direction, respectively. The $a^{*}$ value is given by $a^{*}=C_{\mathrm{ab}} \times \cos \left(h_{\mathrm{ab}}\right)$. The colors (red and orange) appearing at low $\mathrm{pH}$ values (see Fig. 1) correspond to small hue angles. This 


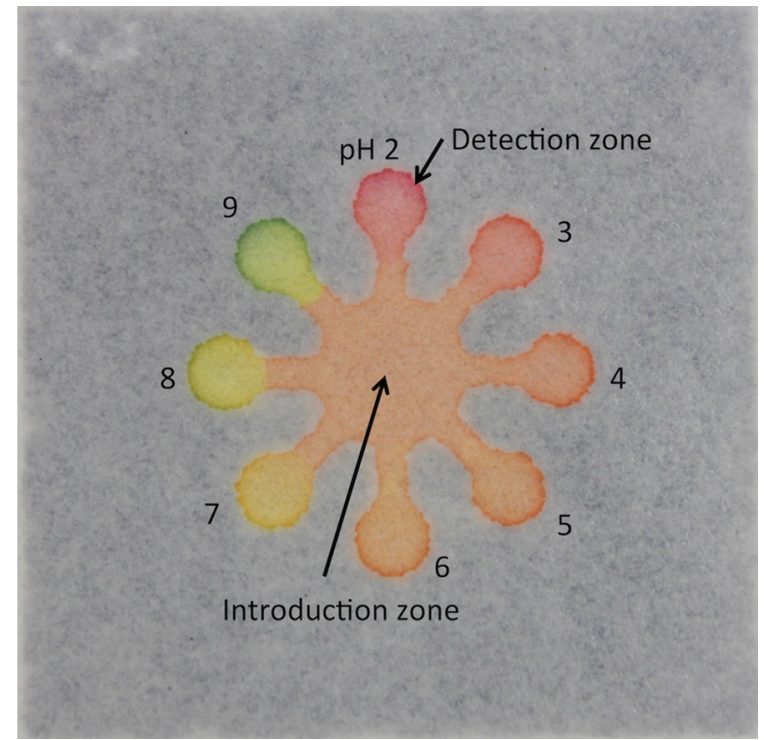

Fig. 1 Photograph of the $\mu \mathrm{PAD}$ producing multiple colors for various $\mathrm{pH}$ values (2-9). The $\mu$ PAD had eight detection zones $(\varphi=4 \mathrm{~mm})$ and an introduction zone (center part, $\varphi=12 \mathrm{~mm}$ ). Aqueous solutions $(0.5 \mu \mathrm{L}$ ) with different $\mathrm{pH}$ values were introduced into separate detection zones and the universal $\mathrm{pH}$ indicator $(15 \mu \mathrm{L})$ was added to the introduction zone.

resulted in the small change in the $a^{*}$ coordinate as shown in Fig. S3. $\uparrow$ Thus, only the use of the $a^{*}$ value is not suitable for $\mathrm{pH}$ measurement based on formation of multiple colors. Commonly, multiple-color changes have gained great attention in various assays, such as heavy metal assay ${ }^{23}$ and enzymatic assay, ${ }^{24,25}$ which could be applicable to $\mu \mathrm{PAD}$ formats. Therefore, we examined if the quantitative measurement of $\mathrm{pH}$ could be performed by using $\Delta E$ for multiple color changes because $\Delta E$ contains much color information.

We fabricated $\mu$ PADs by the previously reported screenprinting method. ${ }^{26}$ The $\mu \mathrm{PAD}$ had eight detection zones (diameter, $4 \mathrm{~mm}$ ) and an introduction zone (diameter, $12 \mathrm{~mm}$ ). The detection zones were connected to the introduction zone via microchannels (width $=2 \mathrm{~mm}$ ). In brief, a piece of chromatography paper was fixed onto a printing table. A patterned screen stencil was placed onto the paper and the paper was kept in place on the printing table via a vacuum pump. Then, PDMS was poured onto the screen stencil, and a squeegee was used to rub the PDMS into the pattern openings. The PDMSprinted paper was cured in an oven at $120^{\circ} \mathrm{C}$ for $30 \mathrm{~min}$. The patterned paper was removed from the oven and cut into separate paper devices $(30 \times 30 \mathrm{~mm})$.

In the $\mathrm{pH}$ measurement with the $\mu \mathrm{PAD}, 0.5 \mu \mathrm{L}$ portions of aqueous solutions prepared at various $\mathrm{pH}$ values were introduced into the respective detection zones. After a $5 \mathrm{~min}$ incubation at room temperature, $15 \mu \mathrm{L}$ of a universal $\mathrm{pH}$ indicator (the composition and the concentration are shown below and in the ESI $†$ ) was introduced into the introduction zone. After a 1 min incubation, a digital image of the $\mu \mathrm{PAD}$ was taken with a digital camera (EOS Kiss X6i, Canon, Tokyo, Japan) under fluorescent lighting conditions. The distance between the $\mu \mathrm{PAD}$ and the camera was fixed to $c a .20 \mathrm{~cm}$. The color information was obtained with an image analysis software program (ImageJ ver. 1.48).

To perform the $\mathrm{pH}$ measurement in a wide range of $\mathrm{pH}$ values, we used a universal $\mathrm{pH}$ indicator consisting of thymol blue ( $\mathrm{p} K_{\mathrm{a}_{1}}=1.7, \mathrm{p} K_{\mathrm{a}_{2}}=8.9$; transition intervals, $\mathrm{pH} 1.2-2.8$ and $\mathrm{pH}$ 7.8-9.5), methyl red ( $\mathrm{p} K_{\mathrm{a}}=5.1, \mathrm{pH}$ 4.2-6.2), bromothymol blue $\left(\mathrm{p} K_{\mathrm{a}}=7.1, \mathrm{pH}\right.$ 6.0-7.6), and phenolphthalein $\left(\mathrm{p} K_{\mathrm{a}}=9.3\right.$, $\mathrm{pH} 7.8-10.0) .^{9}$ Fig. 1 shows a photograph of the $\mu$ PAD, showing that the $\mathrm{pH}$ indicator exhibited various colors, such as red, orange, yellow and green in response to the $\mathrm{pH}$ values of test solutions ( $\mathrm{pH} 2-9)$ at the detection zones.

We analyzed the color of the detection zones in the digital images in the typical RGB color space and the CIE $L^{*} a^{*} b^{*}$ color space. For the image analysis in the CIE $L^{*} a^{*} b^{*}$ color space, the image was converted from the RGB color space to the CIE $L^{*} a^{*} b^{*}$ color space with the Color Space Converter plugin in the image analysis software and then separated into respective channels of $L^{*}, a^{*}$, and $b^{*}$. A circular region of interest (ROI, 27000 pixels) was selected around each detection zone and was analyzed using the software, as shown in Fig. S1† (a red dotted circle). The RGB values, grayscale, and respective $L^{*} a^{*} b^{*}$ values of the selected region were obtained with the software. Each value was given as a mean in the region. Thus, the nonuniformity in the colors in each zone was flattened. Consequently, the non-uniformity had little effect on the assay results. We performed the assay in triplicate.

Fig. 2(a) shows plots of RGB values against the $\mathrm{pH}$ value. A plot of grayscale against the $\mathrm{pH}$ value was also prepared for reference (Fig. S2 $\dagger$ ). The RGB values and grayscale showed no monotonic change in response to the $\mathrm{pH}$ value of 2-9 and narrow detectable $\mathrm{pH}$ ranges with RGB values. This is due to the lack of color information because the respective RGB values show only the information of redness, greenness or blueness of the resulting colors. We also considered that large standard deviations were caused by the reproducibility of colors of the photograph. Therefore, the RGB value is not suitable for $\mathrm{pH}$ measurement in the $\mu \mathrm{PAD}$ giving multiple colors.

Next, the image analysis with the CIE $L^{*} a^{*} b^{*}$ color coordinates $\left(L^{*}, a^{*}\right.$, and $\left.b^{*}\right)$ was performed. Fig. S3† indicates that the data points traced an arc, accompanying an increase in the $\mathrm{pH}$ value. Fig. $\mathrm{S} 4 \uparrow$ also shows dependencies of the $\mathrm{pH}$ value on each coordinate $\left(L^{*}, a^{*}\right.$, and $\left.b^{*}\right)$. The $a^{*}$ value was decreased with increasing $\mathrm{pH}$ value. However, the $a^{*}$ value shows no significant change at low pHs because of large standard deviation as shown in Fig. $\mathrm{S} 4, \dagger$ which suggests that the $\mathrm{pH}$ cannot be measured with the $a^{*}$ value. The $b^{*}$ value and the $L^{*}$ value did not show monotonic changes in response to the $\mathrm{pH}$ value of 2-9 (Fig. S4†).

The color difference $(\Delta E)$ was calculated using eqn (1) with the values of $L_{0}^{*}, a_{0}^{*}$, and $b_{0}^{*}$ for the color produced at $\mathrm{pH}$ 2. Fig. 2(b) shows that the $\Delta E$ value increased monotonously with increasing $\mathrm{pH}$ value with small standard deviations. This confirmed high assay reproducibility. The detectable $\mathrm{pH}$ range was wider than those obtained with the RGB-based image analysis and the single channel value of $L^{*}, a^{*}$, and $b^{*}$. For com- 

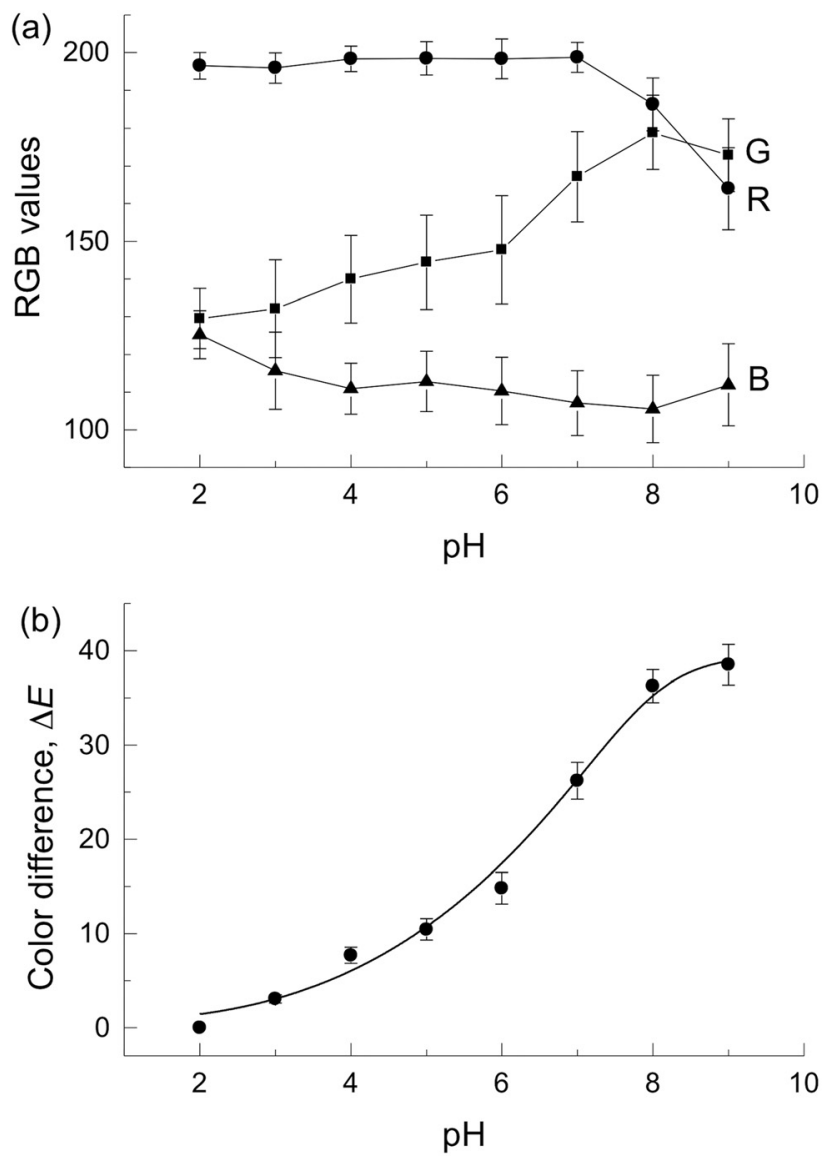

Fig. 2 Plots of (a) R, G, and $B$ against $p H$ value and (b) plot of $\mathrm{CIE}$ $L^{*} a^{*} b^{*}$ color difference against $\mathrm{pH}$ value. Data points represent the mean of 3 measurements and error bars represent one standard deviation from the mean. In panel (b), data were fitted to a sigmoidal curve $\left(R^{2}=0.982\right)$.

parison, a $\tan ^{-1}\left(b^{*} / a^{*}\right)^{15}$ vs. pH value plot was constructed (Fig. S5 $\dagger$ ) because $\tan ^{-1}\left(b^{*} / a^{*}\right)$ contains the hue information as well as $\Delta E$. The $\tan ^{-1}\left(b^{*} / a^{*}\right)$ showed a linear relationship with the $\mathrm{pH}$ value in the range of $2-9\left(r^{2}=0.972\right)$. However, the $\tan ^{-1}\left(b^{*} / a^{*}\right)$ values showed larger standard deviation than $\Delta E$ at low pHs.

In conclusion, we demonstrated a simple $\mathrm{pH}$ measurement in the $\mu \mathrm{PAD}$ by a colorimetric method based on the CIE $L^{*} a^{*} b^{*}$ color difference $(\Delta E)$. The use of $\Delta E$ was suitable for a colorimetric $\mathrm{pH}$ measurement based on the multiple color changes due to the universal $\mathrm{pH}$ indicator. We expect that the combination of the $\mu \mathrm{PAD}$ and image analysis based on color difference $\Delta E$ will enable quantitative analysis for multiple color changes. $^{24}$ The present paper-based analytical method will accelerate applications to point of care testing and in resourcelimited settings.

\section{Acknowledgements}

This research was partially supported by the Urakami Foundation for Food and Food Culture Promotion.

\section{References}

1 A. W. Martinez, S. T. Philips, M. J. Butte and G. M. Whitesides, Angew. Chem., Int. Ed., 2007, 46, 1318-1320.

2 D. M. Cate, J. A. Adkins, J. Mettakoonpitak and C. S. Henry, Anal. Chem., 2015, 87, 19-41.

3 Y. Xia, J. Si and Z. Li, Biosens. Bioelectron., 2016, 77, 774-789.

4 L. S. A. Busa, S. Mohammadi, M. Maeki, A. Ishida, H. Tani and M. Tokeshi, Micromachines, 2016, 7, 86.

5 A. W. Martinez, S. T. Phillips, G. M. Whitesides and E. Carrilho, Anal. Chem., 2010, 82, 3-10.

6 A. W. Martinez, S. T. Phillips, E. Carrilho, S. W. Thomas III, H. Sindi and G. M. Whitesides, Anal. Chem., 2008, 80, 3699-3707.

7 W. Dungchai, O. Chailapakul and C. S. Henry, Anal. Chem., 2009, 81, 5821-5826.

8 E. Carrilho, A. W. Martinez and G. M. Whitesides, Anal. Chem., 2009, 81, 7091-7095.

9 S. Karita and T. Kaneta, Anal. Chem., 2014, 86, 1210812114.

10 K. Yamada, T. G. Henares, K. Suzuki and D. Citterio, Angew. Chem., Int. Ed., 2015, 54, 5294-5310.

11 K. Abe, K. Suzuki and D. Citterio, Anal. Chem., 2008, 80, 6928-6934.

12 W. Liu, Y. Guo, M. Zhao, H. Li and Z. Zhang, Anal. Chem., 2015, 87, 7951-7957.

13 N. K. Thom, G. G. Lewis, K. Yeung and C. T. Phillips, RSC Adv., 2014, 4, 1334-1340.

14 N. Hao, M. Xiong, J. D. Zhang, J. J. Xu and H. Y. Chen, Anal. Chem., 2013, 85, 11715-11719.

15 N. Lopez-Ruiz, V. F. Curto, M. M. Erenas, F. Benito-Lopez, D. Diamond, A. J. Palma and F. Capitan-Vallvey, Anal. Chem., 2014, 86, 9554-9562.

16 C. Sicard, C. Glen, B. Aubie, D. Wallace, S. JahanshahiAnbuhi, K. Pennings, G. T. Daigger, R. Pelton, J. D. Brennan and C. D. M. Filipe, Water Res., 2015, 70, 360-369.

17 S. J. Vella, P. Beattie, R. Cademartiri, A. Laromaine, A. W. Martinez, S. T. Phillips, K. A. Mirica and G. M. Whitesides, Anal. Chem., 2012, 84, 2883-2891.

18 X. Mu, L. Zhang, S. Chang, W. Cui and Z. Zheng, Anal. Chem., 2014, 86, 5338-5344.

19 L. Cai, Y. Wang, Y. Wu, C. Xu, M. Zhong, H. Lai and J. Huang, Analyst, 2014, 139, 4593-4598.

20 E. Hirayama, T. Sugiyama, H. Hisamoto and K. Suzuki, Anal. Chem., 2000, 72, 465-474.

21 M. Maskan, J. Food Eng., 2001, 48, 169-175.

22 R. S. Berns, Billmeyer and Saltzman's Principles of Color Technology, John Wiley \& Sons, 3rd edn, 2000.

23 D. Li, X. Sun, M. Wang, H. Yu, H. Zhou, J. Wu and Y. Tian, Sens. Actuators, B, 2015, 220, 1006-1016.

24 A. Ishida, Y. Yamada and T. Kamidate, Anal. Bioanal. Chem., 2008, 392, 987-994.

25 C. Li, Y. Yang, D. Wu, T. Li, Y. Yin and G. Li, Chem. Sci., 2016, 7, 3011-3016.

26 S. Mohammadi, M. Maeki, R. M. Mohamadi, A. Ishida, H. Tani and M. Tokeshi, Analyst, 2015, 140, 6493-6499. 